\title{
Management Model in Strategic Business Units (SBU)
}

\author{
Josefina Morgan Beltrán ${ }^{{ }^{*}}$, Elia Socorro Diaz Nieto ${ }^{2}$, Francisco Javier de Jesús Diaz ${ }^{3}$ \\ ${ }^{1} \mathrm{PhD}$ in Administration and post-doctorate in Education, research professor at the Autonomous University of \\ Querétaro, Mexico \\ ${ }^{2} \mathrm{PhD}$ in Administration with specialization in International Trade and research professor at the Autonomous \\ University of Querétaro, Mexico \\ ${ }^{3}$ Master in senior management from the Autonomous University of Querétaro, Mexico
}

*Corresponding Author: Josefina Morgan Beltrán, PhD in Administration and post-doctorate in Education, research professor at the Autonomous University of Querétaro, Mexico

\begin{abstract}
The objective of this research is to design a management model for SBU administration based on the strengthening of its capacities. The development of research is carried out in 4 phases are planning, internal assessment, external assessment and final report, and l proposed model focuses on 9 criteria considered basic in the excellence of an organization: politics, culture and strategy, collaborators, alliances and resources, leadership, processes, results in people, results in society, key results and results in customers. The results evidenced that the company does not reach a favorable index for each criterion, with important areas of opportunity in its administrative management and in most of its processes. The conclusions are that the organization has favorable elements for the implementation of administrative strategies; the main recommendations were focused on defining strategies and guidelines based on optimizing administrative management, correcting the weaknesses and taking advantage of the opportunities presented by each criterion of the model. proposed management. The relevant aspect of the proposal is the feasibility of being replicated by the other units and even by the organization.
\end{abstract}

Keywords: Management Model, Strategic Business Unit (SBU), Administrative Capabilities

\section{INTRODUCTION}

The dynamism faced by organizations composed of SBU today has led them to maintain a constant struggle to improve all operational processes, which directly or indirectly influence the achievement of individual and organizational goals and objectives. That is why the administrators and managers take responsibility for the actions, giving the opportunity to the rest of the staff, to contribute or contribute knowledge and skills that contribute in the fulfillment of a better model of administrative management, which generates benefits to the company.

For the analysis of administrative management in SBU, it is possible to implement business development tools that allow evaluating the degree of efficiency and effectiveness with which human resources are fulfilling planning, organization, management, coordination, execution and the control of the objectives set by the top management. All this with the purpose of correcting any deficiencies that may exist, having a continuous improvement, optimizing productivity and improving the use of available resources, in accordance with the procedures, norms and policies of a suitable management model for the SBU.

\section{THEORETICAL ASPECTS}

\subsection{Management Models}

Barreiro (2003), defines the management as "the action and effect of managing or managing, is to win, is to conduct diligences conducive to the achievement of a business or any desire."

In another conception, management is defined as "the set of management and administration activities of a company". (p.6)

Franklin (2007) considers the task of building an economically better society; Improved social norms and more effective government is the challenge of modern administrative management. The 
supervision of the companies is in function of an effective administration; To a large extent, the determination and satisfaction of many economic, social and political objectives rest on the competence of the administrator. In complex situations, where a large amount of material and human resources is required to carry out large-scale companies, administration is of paramount importance for the achievement of objectives.

In the sphere of collective effort where the administration acquires its most precise and fundamental significance, be it social, religious, political or economic, every organization depends on the administration to carry out its ends. Franklin(2007).

For some authors, the administration has similar definitions, but it could be conceptualized with the purpose of understanding it easily, focusing on the administrative management model and allowing it to adapt it to the management model that is proposed in the present work, as shown below:

For Koontz \& O'Donnell (2007), the theme of administration includes the direction of a social organism, and its effectiveness in reaching its objectives, based on the ability to lead its members.

For the author Galindo (2006), "the administration comprises a series of knowledge, principles and tools that are indispensable to obtain the maximum efficiency and quality of the results of any type of organization". (p.126)

According to Stoner (2006), the administration consists of shaping, in a conscientious and constant manner, the organizations. This administration is based on the process of planning, directing and controlling the work of the members of the organization and using available resources to achieve the established goals.

For Hurtado (2008), the administrative management is the executed administration, it analyzes it as an important and universal discipline that is based on developing processes to accumulate knowledge that contains scientific principles, theories, concepts and other elements, mentions that; finally, it depends on the ability and skill of administrators or managers to apply them in organizations. The administrative management process includes functions and activities that administrators must carry out in order to achieve the objectives of the organization.

Bearing in mind the previous administration definitions, the definition of the management model will now be analyzed.

Quinn (1994), makes a broad approach to define what is a management model, says that the lives of many people who participate in an organization, both internal and external and even the families of these people, are affected by the actions of those who run the organization. Due to the self-opinion on what should be the performance of a leader, almost never succeeds to the extent that would have been desired. For many leaders, good management means controlled operations, well organized and directed under aggressive and hard leadership. This model is not entirely wrong, but it is inadequate because it prevents awareness of other important alternatives and as a result, is not as effective as it should be.

Pragmatically, each individual has their own belief or opinion about what a leader or leader has to do. In management studies, sometimes, these beliefs or opinions are called "models". There are then many different types of models, some formally described or that are in some way explicit, others are informal. Because the models are directly related and affect what happens inside and outside the organizations, it is necessary to analyze them in detail (Quinn, 1994).

For Quinn (1994), models are "representations of a more complex reality. An airplane model, for example, is a physical representation of a real airplane. The models help us to represent, to communicate ideas about, and to better understand, the most complex phenomena of the real world. “(p.3)

In the organizational environment, a model is often represented as a set of hypotheses, or a general line of thought in relation to some phenomenon, to have a special vision of a reality more complex than what is presented to the naked eye. Although the models help to see certain aspects of a phenomenon, they can also divert attention to important aspects and that during the analysis can be left out being of significant importance to consider them part of the study. 


\subsection{Strategic Business Units}

Kotler (2003), mentions that the first thing that the direction of an organization should focus on is to identify the businesses that are key within the company, these businesses can be called strategic business units:

"A strategic business unit (SBU) is a unit of the company that has a separate mission and objectives and that can be planned independently of the other business of the company. A SBU can be a division of the company, a product line within a division or even a product or individual brand. " ( $\mathrm{p} 51)$

Frances (2006) says that an individual company, whose strategic business unit (SBU) is unique, is considered potentially a corporation since investors and owners can incorporate other businesses if they so decide. He comments that each SBU has its own functions that consist of the activities that must be executed to add value to the inputs, transforming them into products to penetrate the markets to which the product or service that is offered is destined, the activities that are developed In each SBU they are marketing, production, human resources, supplies and finance.

The SBU, can be considered as an individual company, together, each strategic business unit is considered as the fundamental component of the corporations. Considering that each SBU has its own functions of marketing, production, finance, human resources and supplies, in the economic sense, each SBU must be a feasible company, with full identification of the market, suppliers and differentiation of its products in order to face its competitors. For the cases in which the companies are multinational, the SBUs can be in different countries, subordinate corporations are established, which in turn are constituted by several SBUs. From the structural point of view of the corporations, the command center is called as a corporate unit, each SBU is called a division. (Frances, 2006).

The characteristics of a SBU raised by Frances (2006) are:

- It represents a financial benefit.

- You have defined your own clients.

- You have fully identified your competitors.

- It may or may not be related to other SBU of the corporation.

- Develop your own business strategies with your own assets.

- It has its own business address.

- It may or may not agree with other units in the structure of the company.

- They can have independence as a legal entity.

Martínez and Milla (2005), comment that a SBU can be detailed as a section of the company whose products or services, marketing, competitors and customers are not the same for the rest of the company's activities, comment that SBUs are supported in 3 basic dimensions:

$>$ The need that satisfies the product or customer service.

$>$ The existence of technology that contributes to customer satisfaction.

$>$ The market segment to which the product or service is directed.

It is very important to have fully identified the needs of the clients, as well as having identified the competence of the SBU is specific, having full identification of these two factors, strategic decisions can be taken to satisfy the target market segment and with it, obtain a competitive advantage for the organization.

For companies whose products are aimed at different markets (diversified companies) or those that are dedicated to vary their activities, the establishment of strategic units is the fundamental point to carry out an essential strategic analysis to enunciate the business strategy. It can include a series of terms that make a difference between the strategic segment of the organization, but, in short, all these terms define the same concept of strategic business units, SBU. (Business management and management, 2004). 
For the company "direction and management of companies" (2004), the reason why organizations choose to establish SBU, is to consider the particularity of the market, the required capacities and the agents of success of each activity of the company in the first place and second, because of the probable similarity between these elements or certain particularities both internal and external of these same activities. Each SBU is then a group of similar activities or businesses from a strategic point of view for the organization, in other words, a specific strategy can be established but at the same time, different from those of other business units, it is understood as such, that each SBU may or may not be autonomous and independent of the other business units without neglecting that they are all constituted by the same business strategy.

Schnaars (1993), says that organizations that choose to implement administrative models based on SBU, allows large companies that have varied products, face the competition by sectioning their activities as if establishing small internal and independent print. Taking into account the previously described, the strategic business units are considered a way to structure a company in such a way that each of the units that make it, focus on a specific product line, is directed to a well identified market and a full knowledge of the competition. Each SBU has its management system independent of other SBU and consequently, its own objectives, each SBU is assigned its own operating resources, costs and benefits by the organization.

The SBUs are structured based on the market to which their products are directed and the type of consumers that acquire them, these two factors are external, each SBU is directed to a specific market with clearly identifiable products, the products can be distributed in different SBU Although sometimes the same manufacturing areas can be shared, finally it is the markets that matter most, not the internally existing similarities of production. Another way to organize SBUs is by clearly identifying their competitors. Each SBU has its own profit center, that is, they operate with full autonomy, each unit has its own direction and objectives, while one unit can project its objective of increasing market share, another could focus its objective on leaving the market . (Schnaars, 1993).

Hax (2004), states that a 1 start the process of strategic planning there is a challenging issue that organizations should consider, and that is to fully identify what type of business they are and they want to venture into the future, the answer This questioning requires knowledge and expertise as it is directly linked to the business segmentation strategy.

Abascal (2004), defines a strategic business unit (SBU) as: " a business area with an external market for goods and services for which one can determine independent objectives and strategies ". (p.25) To be able to implement the business units, a division of the areas is carried out, emphasizing key points about the market to which the product is directed, rather than focusing on the internal resources that the various products they produce may have in common., such as, production lines, machinery, distribution channels, among others. The key points to consider for the definition of SBU are:

$>$ Competition: full identification of competitors.

$>$ Prices: Changes in the prices of all the products of a SBU, should be affected in the same way when applicable.

$>$ Clients: Clear identification of the target market.

$>$ Quality / Style: By maintaining a high level of quality and style in the products, the preference of the customers is also maintained.

$>$ Substitution: In a short term the products of a SBU should be substitutable.

$>$ Disinvestment or Liquidation: All the products of a SBU must have the attribute of being sustainable to maintain the economically viable autonomy.

The term of SBU is still implemented today in companies since these are formally developed and implemented strategic planning processes. (Abascal, 2004).

Manso (2003), refers to the definition of strategic business units SBU as follows: " are considered business units or bodies, composed of one or more products, very determined, which have a common market very limited, at the front of which there is a manager or manager who has the responsibility to integrate all the functions through a business strategy, in front of one or several identifiable competitors " (page 514). There are certain characteristics that companies must have to be considered as SBU, these characteristics are: 
$>$ Possess a unique and differentiated mission and strategy.

$>$ Full identification of its competitors.

$>$ Type of clients perfectly identified.

$>$ Disposition and control of the functions of the business.

The organizations that have opted to follow the SBU model, identified that the traditional decentralized structure model of operation by divisions, did not work efficiently, the focus of this form of work was directed to the production and not to the demanding market, in other words, it was produced in large quantities pretending to sell en masse trying in this way to have a preference in the consumers, without taking into account the type of clients, extracting the maximum profit margin, but this could not be achieved, the reasons that take in account organizations when they rely on the resource to implement SBU are:

- Reaction to the constant changes of the market, for organizations it is important to be up to date and achieve a timely identification and differentiation to the product-market issue.

- Organizations that have a wide variety of products and are focused on product-market, should be directed so that each SBU focuses on one or more product-market identified fully, with a specific business strategy and differentiated from the other SBU.

- The strategy designed for each SBU must be in accordance with its own needs and competitive possibilities, although always aligned with the overall vision of the organization.

- All business units that make up the organization are managed and managed with resources, according to how the organization decides and agrees to achieve the general objectives and essential benefits, the business must be designed and managed to achieve a general business strategy.

Coate (1983), states that large organizations that have a wide variety of products, can be segmented into separate strategic business units (SBU), this approach implies that the activities carried out by a business unit (production, marketing, etc.) are not related to the activities carried out by other units that make up the business portfolio. The synergistic effects that may exist in the portfolio are not taken into consideration and the production functions and the demand of the business units are considered to be additive in nature.

The difficulties or inconveniences that arise when the SBUs are implemented are related to the following aspects:

- The independence and autonomy of strategic business units.

- The measures of the domain of the market or sector.

- The problems related to the determination of the degree of attractiveness of the sector.

- Financial restrictions and liquidity recycling.

- The consideration of risk in strategic decisions.

- The positioning in the matrix and the degree of uncertainty.

- The absence of creativity and the psychological impact.

- The generation of new strategic business units.

- The application of criteria of rationality.

- The validity of the strategies.

- The control of the competitors.

According to Hax and Majluf (1993), a concept that has been developed and that involves many potentials for the strategic segmentation of organizations is that of strategic business units. This constitutes a different mode of segmentation, oriented by the markets in which the different businesses of the organization move. The purpose of the SBUs is to serve an external market, which is 
why their competitors and their clients must be adequately defined. For this same reason, it is required that the manager in charge of the management of the unit has the necessary autonomy to be able to operate its strategic unit. The decision to structure an organization according to its strategic business units must be based on a careful analysis of the external environment, on a study of internal strengths and weaknesses and on the definition of the business mission.

By giving space to the consideration of the aforementioned dimensions, the segmentation of the activities of the organization is irremediably produced, according to the criteria considered relevant. In this regard it is convenient to point out that, segmentation (Figure 1)does not have to be based on a sing le criterion, since it can happen, and it is very likely that this is the case, that in order to segment different dimensions are taken into account. Thus, it is possible for a segmentation to be made while attending to functional, geographical, market and product considerations at the same time. (Hax and Majluf, 1993).

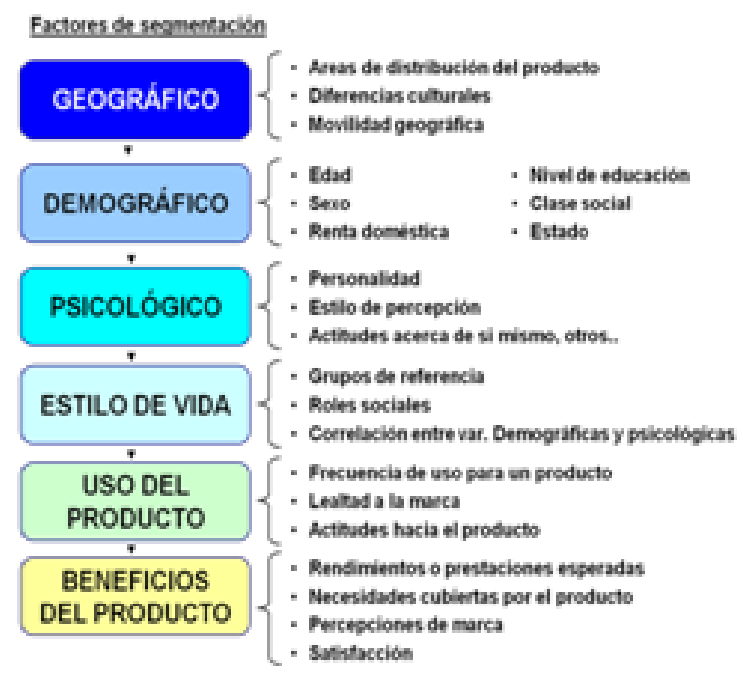

Figure1. Market segmentation

Source: David (2014, p 279).

The business segmentation that implies the constitution of a SBU must take into account the synergy that results from the potential interrelations between the different business units of the same corporation.

The SBUs are not designed to exist only in large companies, also small organizations can define the design of their own SBU, as a model of management and development, which has proven its virtues and which successfully contributes to managing different products and markets. The daily management of the SBU is like that of any company, in practice it is considered as "a company within another company", its levels of execution and performance will depend on the markets and products it serves and its complexity, the complexity of the same. Business and the competition that it faces, the coordination with the other SBUs is exercised more at a corporate and strategic level than at a functional level.

\section{Methodological ASPECTS}

\subsection{General Purpose}

To propose an administrative management model for one of the SBUs that make up the organization based on the strengthening of its institutional capacities through the use of situational strategic planning.

\subsection{Specific Objectives}

$>$ Evaluate the theories to be used in the development of the administrative management model to be used.

$>$ Define the administrative management model to be used in companies composed of SBU.

$>$ Determine the conclusions and recommendations that the project would yield. 


\subsection{Investigation Questions}

$>$ What would be the best model of administrative management for a SBU within an organization, which solves the problems regarding the definition and delimitation of the management model, and thedegree of responsibility and autonomy of each SBU?

$>$ What benefit does the implementation of an adequate model of administrative management in a SBU generate?

\subsection{Proposition}

An optimal model for the administrative management of a SBU should focus on the basic elements for the excellence of an organization that includes Planning, Evaluations and Results with clearly defined indicators that strengthen the organizational structure in its policies, processes, people and external environment.

The SBUs that have a well defined and defined administrative management model that clearly establishes the degree of responsibility and autonomy, are more effective because they facilitate the operation of the organization by clearly identifying the processes and generating greater satisfaction in the clients when effective compliance with the service is achieved.

\subsection{Case Study}

The case study company belongs to the metallurgical industry turning to the manufacture of gas and liquid passage valves, having as market the gas, energy and agrochemical industry, has a staff of 96 administrative workers and operators, this has brought with it a series of benefits and problems inherent to an unplanned growth and a lack of administrative organization. During the 15-year period since it was established, the company has maintained continuous growth, starting operations with a staff of 22 administrative workers and operatives.

With a distribution of 49 manufacturing plants throughout the world and its continuous expansion, the company arrives in the city of Queretaro in 2001 taking advantage of the attraction of American companies by an already established group, offering an early start-up under the name of the group, but integrating as a strategic business unit.

\section{RESUlts}

The research was carried out in the case study company through the application of semi-structured interviews carried out to employees and executives of the organization and the phenomenology was taken into account, which is the opinion of the interviewees on the subject in question, is also considered a transversal research that means giving the context to the research in time, space and the circumstances in which it develops.

The results are presented by empirical indicators themselves that are derived from the study variables.

\subsection{Belonging}

The interviewees commented that the main reasons why they like to work in the organization are:

- Because they gave me the opportunity to work. It is close to where I live and there is also a good work environment, I always learn something new.

- It gives me the opportunity to work on what is right for me and to grow professionally.

- It is a good job, it gives me economic stability and I have the opportunity to lead an internationally renowned company, my duty is to maintain the required standards at the highest level.

\subsection{Identity}

Regarding the raison d'être of the company, the products they manufacture, the clients and the competition, the interviewees commented:

- I do not know what the company's raison d'être is, they make valves for the oil industry, I do not know who the customers are and I do not know if there is competition either.

- I think it is to make valves for oil and gas, buy them in the United States, I do not know if there is another company that does the same. 
- The raison d'être of the company is defined in the mission, in this it is mentioned that we do and also to what market sector the products are directed, I know that there are companies in Argentina and Spain that make the same products that we do. Being within a group of companies, the mission that is disseminated to the staff is that of the group, this causes a lot of confusion since it differs a lot from what the SBU really is.

\subsection{Communication}

According to the communication that the company makes to inform about the objectives, those who raised them, those responsible for compliance, how to measure them and the strategies to achieve them, the interviewees commented that:

- Every year, they tell us what the objectives are going to be, but they do not say why or where they come from, all year long they tell us how we are doing and what we have to do when we are bad.

- We are informed of the objectives and they are published so that we all know them, we are all responsible for them to be fulfilled doing our work well, they measure each month and the responsible ones make the adjustments and improvements to maintain or improve them.

- It is informed of the objectives of all staff and published in blankets to be present throughout the year, are raised based on the requirements of our parent plant in the USA, each area of the SBU has certain objectives as responsibility and leaders of area they carry the measurement publishing each month the status, in this way all the staff knows how each goal goes, also the leaders are the ones who make the adjustments or changes to reach them.

- What the interviewees consider about communication in general is:

- It is a topic that has not been given the importance it deserves, sometimes only the bosses are informed about certain situations and it is not disseminated to lower levels. Keeping us well informed of the situation of the company can help us to do our job better.

- Even when you have good means to be in constant communication, sometimes communication does not flow, this is more due to the omission of the responsible persons in which the information is disseminated, all are very accessible, but sometimes it is left alone in some people.

- We have several means that I consider good to keep us communicated, although not all are given an appropriate use, I also believe that if on some occasion there is not a good communication, it is more responsibility of the people than the media, participation is It gives in weekly meetings, boards, post office, mailbox, etc.

\subsection{Operations}

Regarding whether the productive processes are efficient or if they consider that they can be improved, the interviewees said that:

- It seems to me that the flow of production is good from receipt of materials to finished product, there are some things that can be improved even when it is not bad as it is done.

- The processes are good, it is very useful to have well defined routes for each part number, there are some orders that lack operations and are made out of the route, this is what is needed to have the processes well controlled.

- Our processes have changed a lot, the list of part numbers has increased, with the incorporation of process engineers the routes have been streamlined and each new part number is submitted to the review process to define the best way to process them, missing review many of those that were already done, but in general I think our processes are good and of course we can improve them even more.

\subsection{Improvement}

Regarding whether the company promotes participation in process improvement activities, provide creative ideas and take them into account, the interviewees consider that: 
- We do not have much participation in these aspects, although we have been asked to give ideas, I do not know if someone has contributed them and has been heard or taken into account.

- If we are asked to contribute ideas for improvement, but only those who have a problem in their work, propose how to solve it, the adjusters are those who are more involved in this and if and I see that they do things to improve the processes.

- Area leaders and supervisors are constantly asked to encourage the participation of people in how? or what to do? to make their work more efficient, they have had good ideas and they have been put into action, some others are not feasible and they are explained to the person who proposed it, because it will not be done so as not to demotivate them. All ideas are taken into account.

\section{CONCLUSION}

\subsection{Model Management Proposal for SBU}

A case study has been made to know the administrative management model of a SBU. To develop this study, a management model has been proposed that will serve as a reference to analyze the categories involved during the administrative process of a SBU that include the definition of the logic of value and its strategic benefits, its alignment with the strategic objectives of the organization and management mechanisms that involve administration, operation and marketing variables.

The proposed model will allow organizations composed of SBU, in addition to facing evaluation systems, to be able to efficiently operate at all levels. This model has the particularity of taking into account that it applies to both small and large companies. For all these reasons, it has been considered opportune to develop a system of indicators that serves as a reference to the issues that arise in the evaluation section of the management model proposed for SBU. This system of indicators must necessarily be adapted and complemented by each SBU, through the identification of processes, resource systems and people, and the establishment of individualized methods for evaluating performance and user satisfaction, both internal as external to each strategic business unit.

The model serves as a point of reference for organizations to make an internal diagnosis of the status of their management, through self-assessment. Although the self-evaluation is designed for the entire organization, it can also be evaluated, a department, a unit or a service in isolation. This selfevaluation allows identifying the strengths and areas for improvement and recognizing the most important deficiencies so that action plans for improvement can be suggested.

The model focuses on the elements that it considers basic in the excellence of an organization. In the following figure, the structure of the proposed model for the administrative management of a SBU is shown graphically (Figure 2)

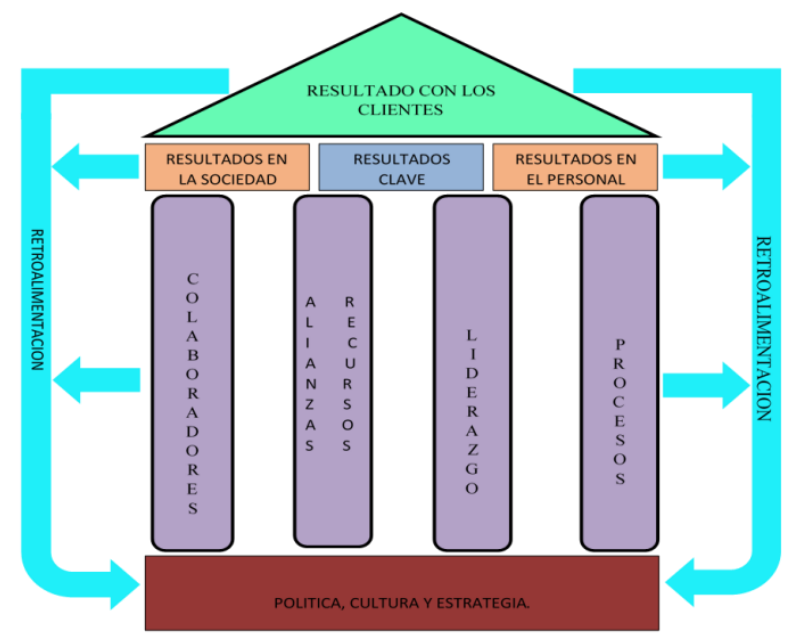

Figure2. Management model proposed for $S B U$

Source: Own elaboration based on information provided by the company. 
The focus of each of the elements or criteria can be summarized as follows:

$>$ Politics, culture and strategy. The organization that is evaluated implements its mission and vision through a strategy supported by policies, plans, objectives and processes, until reaching and maintaining an organizational culture appropriate to its raison d'être.

$>$ Collaborators Management, development and empowerment of people in the organization, with the aim of supporting the policy, strategy and organizational culture through constant improvement.

$>$ Alliances and resources. Planning and management of internal resources and relationships with partners, in order to ensure the achievement of objectives.

$>$ Leadership. Visible commintment of managers in the creation of quality values.

$>$ Processes Design, management and improvement of processes in order to generate added value and satisfy all parties involved.

$>$ Results in the personnel. Degree of satisfaction of the people of the organization, measured through the collection of opinions and internal indicators.

$>$ Results in society. Degree of satisfaction of needs and expectations at local, national or international level, measured through the collection of opinions and internal indicators.

$>$ Key results What the organization is achieving with respect to the most significant expected results.

$>$ Results in the clients. Degree of satisfaction of the different markets or customers, measured through the collection of opinions and internal indicators.

\section{REFERENCES}

[1] Barreiro F.J.M. (2003). Gestión científica empresarial, España: Netbiblo.

[2] Franklin E. B. (2007). Auditoria administrativa. México: Pearson.

[3] Koontz H. y O’donnell C. (2007). Administración moderna. México: Mc Graw Hill.

[4] Galindo M. L. (2006). Fundamentos de administración. Casos y prácticas. México: Trillas.

[5] Stoner J., Freeman R. y Gilbert D. Jr. (2006). Administración. México: Pearson.

[6] Hurtado D. (2008). Principios de administración. Colombia: Fondo editorial ITM.

[7] Quinn E., Faerman R., Thompson P. y McGrath R. (1994). Maestría en la Gestión de Organizaciones. España: Ediciones Díaz de Santos.

[8] Kotler P. (2003). Gary Armstrong. Fundamentos del marketing. México: Pearson.

[9] Francés A. (2006). Estrategia y planes para la empresa. México: Prentice Hall.

[10] Martinez D. y Milla A. (2005). La elaboración del plan estratégico y su implantación a través del cuadro de mando integral. España: Altaír.

[11] Dirección y gestión de empresas. (2004). Dirección estratégica. España: Vértice.

[12] Schnaars S. (1993). Estrategias de marketing. España: Diaz de santos S.A.

[13] Hax A. C. (2004). Estrategias para el liderazgo competitivo. Argentina: Granica S. A.

[14] Abascal F. (2004). Como se hace un plan estratégico. España. ESIC.

[15] Manso F. J. (2003). Estrategia Empresarial. España: Diaz de Santos.

[16] Coate J. (1983). Conceptos estratégicos. México: Prentice Hall.

[17] Hax A. C. y Majluf N. (1993). Administración estratégica. Argentina: Mc Graw-Hill.

[18] David F. R. (2014). Conceptos de administración estratégica. España: Pearson.

\section{AUTHOR'S BIOGRAPHY}

Josefina Morgan Beltrán holds a doctorate in administration, post-doctorade in Education, belongs to the National System of level 1 Researchers in Mexico, and has 35 years of teaching experience and in the productive sector of the country. She is a research professor at the Universidad Autónoma de Querétaro, Mexico.

Elia Socorro Diaz Nieto holds a PhD in Administration with a specialty in International Trade and extensive experience in the productive sector of the country, with more than 30 years in teaching and 
research professor at the Autonomous University of Querétaro, Mexico

Francisco Javier De Jesús Díaz, is a Master in Management in senior management from the Autonomous University of Querétaro, Mexico

Citation: Josefina Morgan Beltrán, Elia Socorro Diaz Nieto, Francisco Javier de Jesús Diaz. "Management Model in Strategic Business Units (SBU) "International Journal of Managerial Studies and Research (IJMSR), vol 6, no. 4, 2018, pp. 1-11. doi:http://dx.doi.org/10.20431/2349-0349.0604001.

Copyright: () 2018 Authors. This is an open-access article distributed under the terms of the Creative Commons Attribution License, which permits unrestricted use, distribution, and reproduction in any medium, provided the original author and source are credited. 